\title{
Examination of the Relationship Between the Social Skills and I nternet Addiction of Preschool Teachers
}

\author{
Hülya Gülay OGELMAN*
}

\author{
Özlem KÖRÜKÇÜ ${ }^{* *}$ \\ Gökhan KÖRÜKÇÜ $\ddot{H}^{* * * *}$
}

\author{
Hande GÜNGÖR ${ }^{* * *}$
}

Received: 29 April 2014

Accepted: 14 November 2014

\begin{abstract}
The purpose of this study is to reveal whether social skill levels of preschool teachers have a predictor effect on the internet addiction or not. The sample group of the study consists of 150 teachers rendering service in kindergarten classes at primary schools of Denizli Provincial Directorate for National Education, as well as independent kindergartens and practice kindergartens. In the study, Social Skills Inventory (SSI) was used to measure the social skill levels of teachers and Internet Addiction Scale (IAS) was used to measure their internet addiction. According to results, there is a significant relationship between the internet addiction levels of teachers and all the subscale levels of social skills. According to this result, as level of one of the subscales of social skills increases, the internet addiction decreases and as the social skill level decreases, the internet addiction level increases. In addition, the internet addictions of preschool teachers are predicted by the social sensitivity skills, which are among the social skills, at most. They are followed by social control, emotional control and emotional expressivity.
\end{abstract}

Keywords: social skill, internet addiction, pre-school teachers

\section{Extended Abstract}

Purpose and Significance: The purpose of this study is to reveal whether social skill levels of preschool teachers have a predictor effect on the internet addiction or not. Subgoals of the study are as follows:

1. Does the emotional expressivity, which is among the social skill variables, significantly predict the internet addiction of preschool teachers?

2. Does the emotional sensitivity, which is among the social skill variables, significantly predict the internet addiction of preschool teachers?

3. Does the emotional control, which is among the social skill variables, significantly predict the internet addiction of preschool teachers?

4. Does the social expressivity, which is among the social skill variables, significantly predict the internet addiction of preschool teachers?

5. Does the social sensitivity, which is among the social skill variables, significantly predict the internet addiction of preschool teachers?

6. Does the social control, which is among the social skill variables, significantly predict the internet addiction of preschool teachers?

\footnotetext{
*Assoc. Professor, Pamukkale University, Denizli, Turkey, hgulay@pau.edu.tr

** Assist. Professor, Pamukkale University, Denizli, Turkey, okorukcu@pau.edu.tr

*** Corresponding Author: Lecturer, Pamukkale University, Denizli, Turkey. hgungor@pau.edu.tr

**** Statistician, Turkish Statistical Institute, Denizli, Turkey, gokhan.korukcu@tuik.gov.tr
} 
Methods: The sample group of the study consists of 150 teachers rendering service in kindergarten classes at primary schools of Denizli Provincial Directorate for National Education, as well as independent kindergartens and practice kindergartens. 146 of them (96.0\%) are female and 6 (4.0\%) are male.

In the study, Social Skills Inventory (SSI) was used to measure the social skill levels of teachers and Internet Addiction Scale (IAS) was used to measure their internet addiction.

Social Skills Inventory (SSI). Being developed by Riggio in 1986, this scale was revised in 1989 and adapted into Turkish by Yüksel (1998) with the participation of university students. Social Skills Inventory is a five-point Likert scale with 90 items aimed at measuring the basic social skills and identifying the self. Social Skills Inventory measures six different areas. It includes the subscales of Emotional Expressivity (EE) measuring the non-verbal expression skills of individuals with their styles of sending especially the affective messages and the non-verbal expression styles of interpersonal interaction tendencies; Emotional Sensitivity (ES) measuring the skills of receiving and interpreting the non-verbal communications of others; Emotional Control (EC) measuring the skills of individuals to regulate and control the affective and non-verbal reactions; Social Expressivity (SE) measuring the verbal expressionism of individuals and their skills to establish a social communication with each other and participate in the communication; Social Sensitivity (SS) measuring the skills of interpreting the verbal communications of others; and Social Control (SC) measuring the social role-play and skills of individuals to socially present themselves. Each subscale includes 15 items. 32 items are structured in a way to be coded reversely. Besides, the scale could also use the total score. In this study, the internal consistency (Cronbach alpha) coefficient concerning the total score was determined as .92 and the internal consistency coefficients that were obtained for the subscales were calculated as follows: .68 for Emotional Expressivity, .76 for Emotional Sensitivity, 72 for Emotional Control, .78 for Social Expressivity, .74 for Social Sensitivity, and .68 for Social Control.

Internet Addiction Scale (IAS). The "Diagnosis Questionnaire" that was adapted by (Young, 1996) from the "Pathological Gambling" of DSM - IV was then improved, which resulted in forming an "Internet Addiction Scale" with 20 questions. The scale was adapted into Turkish by Bayraktar in 2001 with a study that was conducted with adolescents aged between 12-17 years. Being a Likert scale, the Internet Addiction Scale requires the participant to mark one of the following options; "Never" "Rarely" "Sometimes" "Usually" "Very frequently" and "Always". These options are respectively scored as $0,1,2,3,4$ and 5 . In the assessment, those who received 80 scores and above are defined as "internet addicts"; those receiving 50-79 scores are defined as "showing a limited symptom" and those receiving 50 scores and below are defined as "showing no symptom". The Cronbach Alpha coefficient of the Turkish version of the scale is .91 and the Spearman-Brown value is .87 (Bayraktar, 2001). 
Results: According to results, there is a significant relationship between the internet addiction levels of teachers and all the subscale levels of social skills. Accordingly, there is a negative and significant relationship between the internet addiction levels of teachers and their Emotional Expressivity $(\mathrm{r}=.247, \mathrm{p}<.001)$; Emotional Sensitivity ( $\mathrm{r}=$ $.167, \mathrm{p}<.05)$; Emotional Control $(\mathrm{r}=.301, \mathrm{p}<.001)$; Social Expressivity $(\mathrm{r}=.164, \mathrm{p}<.05)$; Social Sensitivity $(\mathrm{r}=.363, \mathrm{p}<.001)$; Social Control $(\mathrm{r}=.319, \mathrm{p}<.001)$ levels. According to this result, as level of one of the subscales of social skills increases, the internet addiction decreases and as the social skill level decreases, the internet addiction level increases.

Besides, it is observed that teachers' Emotional Expressivity $\left(\mathrm{R}=.25, \mathrm{R}^{2}=.061\right.$, $F(1.148)=9.635)$, Emotional Control $\left(\mathrm{R}=.30, \mathrm{R}^{2}=.090, \quad F(1.148)=14.721\right)$, Social Sensitivity $\left(\mathrm{R}=.36, \mathrm{R}^{2}=.132, F(1.148)=22.422\right)$ and Social Control $\left(\mathrm{R}=.32, \mathrm{R}^{2}=.102\right.$, $F(1.148)=16.753)$ levels, which are among the social skill subscales, significantly predict their internet addiction levels.

It could be asserted that some subscales of social skills such as emotional expressivity explains $6 \%$ of the variance concerning the internet addiction level, emotional control $9 \%$, social sensitivity $13 \%$ and social control $10 \%$. According to the standardized regression coefficients (ß), the relative importance order of social skill subscales of preschool teachers on their internet addictions are as follows; (1) social sensitivity (2) social control (3) emotional control, and (4) emotional expressivity skills. According to these results, the internet addictions of preschool teachers are predicted by the social sensitivity skills, which are among the social skills, at most. They are followed by social control, emotional control and emotional expressivity. In addition, the subscales of social expressivity and emotional sensitivity, which are among the subscales of social skills, significantly predict the internet addictions of preschool teachers.

Discussion and Conclusions: This study has found that teachers' skills related to their social sensitivity, social control, emotional control and emotional expressivity are significant predictors of teachers' internet addiction. On the other hand, social expressivity and emotional sensitivity of teachers are insignificant for predicting their internet addiction. According to the results, there is a moderately significant negative relationship between the internet addiction levels and social skills of teachers. In addition, a subscale of social skills, i.e., social sensitivity skills, is the most significant predictor of the internet addictions of preschool teachers. It is followed by social control, emotional control and emotional expressivity skills. The results found in this study support the findings reported in the related literature (Batıün ve Kılıç, 2011; Bozoglan vd., 2013; Cam ve Isbulan, 2013; Kurtaran, 2008; Niemz, Griffiths, ve Banyard, 2005; Tutgun vd., 2011). 


\title{
Okul Öncesi Öğretmenlerinin Sosyal Becerileri ve Internet Bağımlılıkları Arasındaki İlişkinin İncelenmesi
}

\author{
Hülya Gülay OGELMAN*
}

\author{
Özlem KÖRÜKÇÜ̈** \\ Gökhan KÖRÜKÇÜ ${ }^{* * * *}$
}

\author{
Hande GÜNGÖR ${ }^{* * *}$
}

Makale Gönderme Tarihi: 29 Nisan 2014

Makale Kabul Tarihi: 14 Kasım 2014

\begin{abstract}
ÖZET: Bu araştırmada, okul öncesi öğretmenlerinin sosyal becerilerinin, internet bağımlılıkları üzerindeki yordayıcı etkisi incelenmiştir. Araştırmanın örneklem grubunu, Denizli il Milli Eğitim Bakanlığı'na bağlı ilkokulların anasınıflarında, bağımsız anaokullarında ve uygulama anaokullarında görev yapan 150 okul öncesi eğitim öğretmeni oluşturmuştur. Veri toplama araçları olarak, Riggio tarafından 1986 yılında geliştirilen ve Yüksel (1998) tarafindan Türkçe'ye uyarlanan, Sosyal Beceri Envanteri (SBE); Young (1996) tarafından geliştirilen ve Türkçe'ye uyarlama çalışması Bayraktar tarafindan 2001 yılında yapılan İnternet Bağımlılı̆̆ı Ölçeği (İBÖ) kullanılmıştır. Verilerin analizinde Basit Doğrusal Regresyon analizinden faydalanılmıştır. Araştırma sonuçlarına göre öğretmenlerin sosyal becerileri ile internet bağımlılıkları arasında olumsuz yönde orta düzeyde anlamlı bir ilişki olduğu belirlenmiştir. Ayrıca öğretmenlerin sosyal duyarlılık, sosyal kontrol, duyuşsal kontrol ve duyuşsal anlatımcılık becerileri internet bağımlılıklarını anlamlı biçimde yordamaktadır. Sosyal anlatımcılık ve duyuşsal duyarlık becerileri ise internet bağımlılıklarını anlamlı düzeyde yordamamaktadır.
\end{abstract}

Anahtar sözcükler: sosyal beceri, internet bağımlılı̆̆ı, okul öncesi öğretmenleri.

\section{Giriş}

İnsan sosyal bir varlıktır. Sosyal ilişkiler kurarak çevresiyle etkileşim içinde bulunur. Bu etkileşimlerin sağlıklı kurulabilmesi için bireyin yeterli sosyal becerilere sahip olması ile mümkün olabilmektedir. Araştırmacılara göre (Cartledge ve Milburn, 1978; Combs ve Slaby, 1998; Hops, 1983; Katz ve McClellan, 1997; Stephens, 1978) sosyal beceri, sosyal durumlarda sergilenen bir davranış biçimidir. Combs ve Slaby (1998) sosyal becerileri, kişilerin başkaları tarafından toplumsal olarak kabul edilmesi ve aynı zamanda öncelikle başkalarına yararlı olan sosyal bağlamda etkileşim kurma yeteneği şeklinde tanımlamışlardır. Sosyal beceri girişkenlik, uyum gösterme kapasitesi, uyum ve uygulama arasındaki uzlaşma yetisi olarak da tanımlanır (Kanning, 2003). Sosyal beceri diğerleri ile etkileşim içinde iken, kendi çıkarları kadar karşısındakilerin de ilgileri, ihtiyaçları ve isteklerini dikkate alabilmektir. Böylece kişi, bireysel çıkarları ile toplumsal çıkarlar arasında bir uyum ve dengeyi sağlayabilecektir (Jarkowski, 2011). Sosyal-duygusal beceriler bireyin yaşamında özgür bir insan olmasını sağlamakta, aynı zamanda demokratik hayatın korunması konusunda büyük önem taşımaktadır. Bu temel becerilerin edinilmesi, yaşamın ilk yıllarında bir gelişim görevi olarak ifade edilirken, sonraki yıllarda ise bireyin yaşamını sürdürebilmesi için gerekli bir önkoşuldur (Pfeffer, 2012).

\footnotetext{
* Doç. Dr., Pamukkale Üniversitesi, hgulay@pau.edu.tr

${ }^{* *}$ Yrd. Doç. Dr., Pamukkale Üniversitesi, okorukcu@pau.edu.tr

*** Sorumlu Yazar: Öğr. Gör., Pamukkale Üniversitesi, Denizli, hgungor@pau.edu.tr

**** İstatistikçi, Türkiye İstatistik Kurumu, Denizli Bölge Müdürlüğü. gokhan.korukcu@tuik.gov.tr
} 
Günlük hayatlarında bireyler aile, iş, arkadaş grupları gibi birçok sosyal ortamda bulunmaktadırlar. Günümüzde teknolojinin ilerlemesiyle sosyalleşme ortamlarının internete taşınması, bireylerin sosyal paylaşımlarda bulunduğu alanlar olan sosyal ağ sitelerini de popüler hale getirmiştir. Sosyal ağ siteleri, "bireyler ve gruplar arasındaki karş1lıklı etkileşimi kolaylaştıran, sosyal dönüt için çeşitli seçenekler sunan ve sosyal ilişkiler yumağı oluşumunu destekleyen yazılımlar" olarak da tanımlanmaktadır (Boyd, 2003; Akt: Mazman, 2009, p. 3). İlk zamanlarda sadece bireysel iletişime imkân sağlayan internet ve sosyal ağ siteleri, son uygulamalar sonucunda birçok kullanıcının eş zamanlı olarak iletişime geçmesine imkân tanımaktadır. Böylece sosyal ağlar, bireylerin birbirleri ile bağlantı kurmak amacıyla en çok tercih ettikleri iletişim ortamı olarak yaygınlaşmaktır (Çetin, 2009). Sosyal ağ sitelerini eşsiz kılan sadece bireylere tanımadıkları kişilerle tanışma fırsatı vermesi değil aynı zamanda kendi sosyal ağlarını paylaşma imkânı sunmalarıdır (Boyd ve Ellison, 2007). "Özellikle paylaşıma dayalı bir sosyal ortamın gerçekmiş gibi sunulduğu sosyal paylaşım ağları, bireylerin duygu, düşünce, durum, resim, video, müzik gibi birçok paylaşımla kurulan sosyal etkileşime zemin hazırlayarak sosyalliğe ve sosyalleşmeye dair eylemleri, aslına uygun bir şekilde yeniden kurgulamaktadır" (Göker, Demir, ve Doğan, 2010, p. 186). Bu siteler aynı zamanda bireylere ortak ilgi alanlarına sahip bireylerle bir araya gelme ve web ortamında kendilerini ifade etme olanağı tanımaktadır (Parlak, 2009). Web ortamında bireyleri bir araya getirerek teknolojinin soğukluğunu ortadan kaldıran sosyal ağ siteleri, geleneksel yüz-yüze iletişimin yarattığı etkiye benzer bir etkiyi sanal ortamlarda yaratmaktadır (Akar, 2010). İnternetin sağladığı iletişim ortamlarında bireyler ayrıca sanal mağazalardan alışveriş yapabilmekte, bir konuya dair ihtiyaç duyulan bilgiye birçok kaynaktan aynı anda kolaylıkla ulaşabilmekte veya dünyanın herhangi bir yerinde meydana gelen bir olayı anında haber alabilmektedir (Çalık ve Çınar, 2009). İletişim alternatifleri, bilgiye hızlı erişim gibi unsurlardan dolayı internet, bilgi çağının en önemli iletişim aracı olarak kabul edilmektedir.

Türkiye'deki internet kullanım oranları da artış göstermektedir. Türkiye İstatistik Kurumu [TÜİK] (2013) verilerine göre evlerin \%49'a yakını internet erişimine sahiptir. 2010 yılı ile karşılaştırıldığında \%7'ye yakın bir artış olduğu görülmektedir (Internet1, 2014). Bu verilerden de anlaşılacağı gibi Türkiye'de bilgisayar kullanımının artan bir şekilde yaygınlaştığı ve kişisel bilgisayar kavramının iş yerlerinden sonra evlerde de hızlı bir şekilde kullanılmaya başlandığı söylenebilir. Günümüzde artık evlerde bilgisayarlardan sonra notebook, tablet ve en son olarak da akıllı telefonların kullanımı yaygınlaşmaktadır. Bu cihazların her birinin ortak özellikleri ise kapasitesi yüksek işletim sistemleri sayesinde oyunlar, sosyal medya ve internet erişimine kolaylik sağlamalarıdır. Evlerde internet erişimini kolaylaştıran teknoloji sonucunda çocukların da artık erken yaşlarda bu cihazları kullanmaya başladıkları söylenebilir. Bu nedenlerden dolayıdır ki geçmişte oyun parklarında ve sokaklarda arkadaşlarla birlikte gerçekleştirilen gerçek etkinlikler olan oyunlar, günümüzde evlerde ya da internet kafelerde video oyunları ve bilgisayar başında gerçekleştirilen sanal etkinlikler haline gelmiştir (Horzum, 2011). Türkiye İstatistik Kurumu (TÜİK) verileri incelendiğinde Türkiye'de bilgisayar kullanma yaşının ortalama 8 olduğu; 6-15 yaş arası çocukların 
\%60.5'inin bilgisayar, \%50.8'inin internet, \%24.3'ünün cep telefonu kullandığı ve 6-15 yaş grubu çocukların interneti kullanma amaçları arasında \%66.8 ile oyun oynamanın ilk sırada yer aldığı görülmektedir (Internet2, 2014). Bu verilere göre dünyada olduğu gibi Türkiye'de de çocukların bilgisayar oyunlarına ayırdıkları zamanda art olduğu söylenebilir. Horzum (2011), bilgisayar oyun bağımlılığını, çocuğun uzun süre oyun oynamayı bırakamaması, oyunu gerçek hayatıyla ilişkilendirmesi, oyunu oynamaktan dolayı görevlerini aksatması ve oyun oynamayı başka etkinliklere tercih etmesi gibi sonuçları olan bir durum olarak tanımlamaktadır. Bilgisayar oyun bağımlılı̆̆ının, çocukların düşmanca davranışlarının anlamlı yordayıcısı olabildiği (Chiu, Lee, ve Huang, 2004); okul ile ilgili performanslarını düşürebildiği (Marko, Skoric, Ching, ve Rachel, 2009) ortaya konulmuştur. Ayrıca bu tür oyunlara bağımlılık eğilimleri yüksek olan çocuklarda diğer çocuklara göre fiziksel saldırganlık, düşmanca tavırlar ve dışlanmada artış (Gentilea, Lynchb, Linderc, ve Walsha, 2004); sosyal becerilerde ise düşüş (Griffiths, Davies, ve Chappell, 2004) görülebildiği belirtilmiştir.

İnternet kullanımının her geçen gün artması, her türlü bilgiye kolaylıkla ve herhangi bir denetim olmadan ulaşılması beraberinde birçok olumsuz sonucu da getirebilmektedir. Son yıllarda internet bağımlılığı kavramıyla da sıklıkla karşılaşılmaktadır (Bozoglan, Demirer, ve Sahin, 2013; Cam ve Isbulan, 2012; Kurtaran, 2008; Odaci ve Berber, 2013; Tutgun, Deniz, ve Moon, 2011). İnternet kullanımına sınırlama getirememe, sosyal veya akademik zararlarına rağmen kullanıma devam etme ve internete ulaşımın kısıtlandığı durumlarda yoğun kaygı duyma gibi belirtilerle kendini gösteren bu bağımlılık türü 1990'lı yılların ortalarından beri psikiyatri alan yazınında yer almakta ve giderek ilgi çekmektedir (Öztürk, Odabaşığlu, Eraslan, Genç, ve Kalyon, 2007). Young (1996) internet bağımlılığını sarhoş edici madde içermeyen bir dürtü kontrol bozukluğu olarak tanımlamıştır. Ceyhan (2008), internet bağımlılığını; çoğu kez zaman kavramını yitirecek ya da temel görevlerini ihmal edecek şekilde aşırı internet kullanımı, kızgınlık, gerginliği de içeren yoksunluk belirtileri, tolerans gelişimi ve yalan söyleme, sosyal geri çekilme gibi durumları içeren olumsuz yansımaların bir arada olması olarak tanımlamaktadır.

Bağımlı olan bireyler interneti eğlence, etkileşim ve hoşnutluk duygularını yaşamak için daha sık kullanmaktadırlar. Başka bir deyişle, internet bağımlılığı ile "internet kullanım süresi” ve "internetin etkileşim amaçlı kullanımı" arasında olumlu yönde ve anlamlı ilişkiler olduğunu gösteren birçok çalışma bulunmaktadır (Yang ve Tung, 2004).

İlgili alan yazın incelendiğinde, internet bağımlılı̆̆ının nedeni olarak araştırmacılar tarafından vurgulanan en önemli nokta, sosyalleşme ihtiyacıdır (Cam ve Isbulan, 2012). Örnek olarak King (1996), internet üzerindeki sosyal hayatın avantajlarını, günümüz şehir yaşantısında kolay kolay kurulamayan sosyal bağlantıları internet üzerinden kurabilmek, yabancılarla kolaylıkla ve risksiz olarak ilişkiye geçebilmek; insanların kendi kendilerini dizginlemeden, özgürce düşüncelerini, duygularını ifade edebilmek; kendilerini göstermek istedikleri yönlerini abartarak gösterebilmek; internet üzerindeki paylaşma ortamlarında ses çıkarmadan diğerlerini 
"dikizleme" olanağına sahip olmak şeklinde sıralamıştır. Cam ve Isbulan (2012), problemli internet kullanımı ile sosyal etkileşim kaygısı arasındaki ilişkiyi inceledikleri çalışmalarında, erkek öğrencilerin kız öğrencilere nazaran daha fazla internet kullanım problemine sahip olduğunu ortaya koymuşlardır. Ayrıca, internet kullanım süresi arttıkça problemli internet kullanım durumunun da arttığını gözlemlemişler ve sosyal etkileşim kaygısının problemli internet kullanımının yordayıcısı olduğuna ulaşılmışlardır. Odaci ve Berber (2013), çalışmalarında, üniversite öğrencilerinde internet bağımlılığı ile çekingenlik ve saldırganlık arasında olumlu yönde ilişki bulmuşlardır. Başka bir çalışmada (Bozoglan vd., 2013) yalnızlık, benlik saygısı ve hayat memnuniyetinin kişinin internet bağımlılığını yordayan değişkenler olduğu belirtilmiştir. Özellikle kişinin yalnızlık algısının internet bağımlılığını açıklamak için en önemli unsur olarak göstermişlerdir. Ayrıca Tutgun vd. (2011), Kore ve Türkiye'deki öğrenciler ile gerçekleştirdikleri çalışmada da yalnızlık ve internet bağımlılığı arasında alan yazındaki birçok çalışmayı destekleyici olumlu yöndeki ilişkiyi vurgulamışlardır.

Okul öncesi dönemde, tüm alanlarda gelişimin hızlı olması ve bu dönemin bireyin hayatındaki kısa ve uzun süreli etkileri açısından büyük bir önemi vardır. Okul öncesi eğitimin başlamasıyla birlikte etkileşim halinde bulunacağı sosyal çevre de annebabalarından sonra öğretmenlerini model alırlar (Durualp ve Aral, 2011). Okul öncesi dönemde öğretmen-çocuk ilişkisinin niteliği çocuğun okula uyumu, akademik başarısı, sosyal becerileri, sosyal konumu gibi birçok gelişim alanını etkileyebilmektedir (Gülay, 2010; Gülay ve Akman, 2009; Pianta, 2001). Görüldüğü gibi, okul öncesi öğretmenlerinin sosyal becerileri düzeylerinin, internet bağımlılıkları üzerindeki etkisinin ortaya konulması büyük önem taşımaktadır. Türkiye'de konu ile ilgili çalışmaların genellikle üniversite öğrencileri ile gerçekleştirildiği görülmektedir (Bozoglan vd., 2013; Kurtaran, 2008; Odaci ve Berber, 2013; Tutgun vd., 2011). Okul öncesi eğitim öğretmenlerinin internet kullanımları ve sosyal becerilerini inceleyen bir çalışmaya rastlanılmamıştır.

Günlük hayatta her alanda meydana gelen değişimler ve gelişimlerin, bilgiyi ve teknolojiyi ön plana çıkarmış ve önemini arttırmış olduğu söylenebilir. İnsanların bu değişim ve gelişimlere uyum sağlayabilmeleri ise onların bilgisayarı tanıma ve kullanma becerilerine sahip olmalarını gerektirmektedir. Bu da insanların, olabildiğince erken yaşlarda bilgisayarla tanışması ve planlı bir bilgisayar eğitiminden geçmesiyle olanaklıdır. Bilgisayarla tanışmak ya da bilgisayar eğitimine başlamak için, okul öncesi y1llar uygun bir dönem olarak değerlendirilebilir (Yaşar, 2004). Kaçar ve Doğan (2010) okul öncesine devam eden 6 yaşındaki çocuklarla yaptıkları çalışmalarında okul öncesi dönemde teknoloji kullanmanın, mevcut olarak uygulanan geleneksel eğitim yöntemine göre daha etkili olduğu sonucuna ulaşmışlardır. Vernadakis, Avgerinos, Tsitskari, ve Zachopoulou (2005), yaptıkları çalışmalarında okul öncesi eğitimde bilgisayar destekli program kullanımının, bu dönem çocuklarının bilişsel, duyuşsal, dil ve okuma yazma becerilerini geliştirdiğini belirtmişlerdir. $\mathrm{Bu}$ bağlamda değişimin ve gelişimin bir parçası olacak olan okul öncesi öğretmenlerinin de görevleri, rolleri, sorumlulukları ve 
sahip olmaları gereken niteliklerinin değişmesi gerekliliği söylenebilir. Öğretmenlerin derslerinde teknolojiyi etkili bir şekilde kullanabilmeleri, önce teknoloji kullanmayı sonra da teknolojiyi derslerine nasıl kaynaştıracaklarını bilmelerini gerektirir çünkü öğretmen bilgisi olmadan kullanılan eğitim teknolojisi zaman kaybı olarak görülmektedir (Chen ve Chang, 2006).

Araştırmanın amac1, okul öncesi öğretmenlerinin sosyal beceri düzeylerinin, internet bağımlılık düzeyleri üzerinde yordayıcı etkisi olup olmadığını ortaya koymaktır. Araştırmanın alt amaçları şunlardır:

1.Sosyal beceri değişkenlerinden duyuşsal anlatımcılık, okul öncesi öğretmenlerinin internet bağımlılığını anlamlı biçimde yordamakta mıdır?

2.Sosyal beceri değişkenlerinden duyuşsal duyarlık, okul öncesi öğretmenlerinin internet bağımlılığını anlamlı biçimde yordamakta mıdır?

3.Sosyal beceri değişkenlerinden duyuşsal kontrol, okul öncesi öğretmenlerinin internet bağımlılı̆̆ını anlamlı biçimde yordamakta mıdır?

4.Sosyal beceri değişkenlerinden sosyal anlatımcılık, okul öncesi öğretmenlerinin internet bağımlılığını anlamlı biçimde yordamakta mıdır ?

5.Sosyal beceri değişkenlerinden sosyal duyarlık, okul öncesi öğretmenlerinin internet bağımlılığını anlamlı biçimde yordamakta mıdır?

6.Sosyal beceri değişkenlerinden sosyal kontrol, okul öncesi öğretmenlerinin internet bağımlılığını anlamlı biçimde yordamakta mıdır?

\section{Yöntem}

\section{Araştırma Modeli}

Öğretmenlerin sosyal beceri düzeylerinin, internet bağımlılık düzeylerini yordayıcı etkisinin incelendiği bu araştırmada, genel tarama modellerinden iki ve daha çok sayıdaki değişken arasındaki değişimin varlığını ve derecesini belirlemeyi amaçlayan ilişkisel tarama modeli kullanılmıştır.

\section{Örneklem Grubu}

Araştırmanın örneklem grubunu, Denizli İl Milli Eğitim Müdürlüğü’ne bağlı ilkokulların anasınıfları, bağımsız anaokulları ve uygulama anaokullarında görev yapan 150 öğretmen oluşturmaktadır. Öğretmenlerin 146's1 (\%96.0) kadın, 6’s1 (\%4.0) erkektir. Öğretmenlerin kıdem yılları 1-10 yıl arasında değişmektedir. Öğretmenlerin 120'si (\%80.0) ilkokullara bağlı anasınıflarında, 27'si (\%18.0) bağımsız anaokullarında, 3’ü (\%2.0) kız meslek liselerinin uygulama anaokullarında görev yapmaktadır.

\section{Veri Toplama Araçları}

Çalışmada, öğretmenlerin sosyal beceri düzeylerini ölçmek için Sosyal Beceri Envanteri (SBE), internet bağımlılıklarını ölçmek için ise İnternet Bağımlılık Ölçeği (İBÖ) kullanılmıştır. 
Sosyal beceri envanteri (SBE). Riggio tarafından 1986 yılında geliştirilen bu ölçek 1989 yılında revize edilmiş ve Yüksel (1998) tarafından üniversite öğrencilerinin katılımıyla Türkçe'ye uyarlama çalışması gerçekleştirilmiştir. Sosyal Beceri Envanteri temel sosyal becerileri ölçmek amacıyla hazırlanmış 90 maddelik, kendini tanımlamaya yönelik, beşli likert tipi bir ölçek niteliği taşımaktadır.

Sosyal Beceri Envanteri altı ayrı alanı ölçmektedir:

Bireylerin sözel olmayan anlatım becerilerini, özellikle de duyuşsal mesajları gönderim biçimleri ile bireyler arası etkileşim eğilimlerinin sözel olmayan anlatım biçimlerinin ölçüldüğü Duyuşsal Anlatımcılık (DA);

Başkalarının sözel olmayan iletişimlerini alma ve yorumlama becerilerinin ölçüldüğü Duyuşsal Duyarlık (DD);

Bireylerin duyuşsal ve sözel olmayan tepkilerini düzenleme ve kontrol becerilerinin ölçüldüğü Duyusal Kontrol (DK);

Sözel anlatımcılığı ve bireylerin birbirleriyle sosyal iletişim kurma ve iletişime katılma becerilerinin ölçüldüğü Sosyal Anlatımcılık (SA);

Başkalarının sözel iletişimlerini yorumlama becerilerinin ölçüldüğü Sosyal Duyarlık (SD);

Sosyal rol oynama ve bireyin sosyal olarak kendini ortaya koyma becerilerinin ölçüldüğü Sosyal Kontrol (SK) alt boyutlarını içermektedir. Her bir alt ölçek 15 maddeden oluşmaktadır. Maddelerin 32 tanesi ters kodlanacak şekilde yapılandırılmıştır. Ayrıca ölçekte toplam puan da kullanılabilmektedir. Yüksel (1998), ölçeğin Türkçe'ye uyarlanması çalışmasında test tekrar test katsayısı tüm envanter için $\mathrm{r}=.92$, alt ölçekler için ise .80 ile .89 arasında (Duyuşsal Anlatımcılık .81, Duyuşsal Duyarlık .87, Duyuşsal Kontrol .80, Sosyal Anlatımcılık .89, Sosyal Duyarlık .88, Sosyal Kontrol .89, ) bulunmuştur. Toplam puana ilişkin iç tutarlık (Cronbach alpha) katsayısı .85 olarak bulunmuş, alt ölçeklere göre elde edilen iç tutarlık katsayıları ise .56 ile .82 olarak (Duyuşsal Anlatımcılık .56, Duyuşsal Duyarlık .80, Duyuşsal Kontrol .75, Sosyal Anlatımcılık .82, Sosyal Duyarlık .72, Sosyal Kontrol .81) hesaplanmıştır. Bu çalışmada toplam puana ilişkin iç tutarlık (Cronbach alpha) katsayısı 92 olarak bulunmuş, alt ölçeklere göre elde edilen iç tutarlık katsayıları ise Duyuşsal Anlatımcılık .68, Duyuşsal Duyarlık .76, Duyuşsal Kontrol .72, Sosyal Anlatımcılık .78, Sosyal Duyarlık .74, Sosyal Kontrol .68 olarak hesaplanmıştır.

İnternet bağımlılık ölçeği (İBÖ). Young (1996) tarafından, DSM-IV’ün "Patalojik Kumar Oynama" ölçütlerinden uyarlanarak oluşturulan "Tanı Anketi” daha sonra geliştirilmiş ve 20 soruluk bir "İnternet Bağımlılık Ölçeği”" oluşturulmuştur. Ölçeğin Türkçe’ye uyarlama çalışması Bayraktar tarafından 2001 yılında 12-17 yaşlarındaki ergenlerle yaptığı çalışma ile gerçekleştirilmiştir. Likert tipi bir ölçek olan İnternet Bağımlılık Ölçeği'nde katılımcıdan "Hiçbir zaman" "Nadiren" "Arada sırada" "Çoğunlukla" "Çok sık" ve "Devamlı" seçeneklerinden birini işaretlemesi istenmektedir. $\mathrm{Bu}$ seçeneklere sirasıyla $0,1,2,3,4$ ve 5 puan verilmektedir. Değerlendirmede, 80 puan ve üzeri alanlar "internet bağımlısı" olarak, 50-79 puan arası 
alanlar "sınırlı semptom gösterenler", 50 puan ve altı alanlar "semptom göstermeyenler" olarak tanımlanmıştır. Ölçeğin Türkçe formunun Cronbach Alpha katsayısı .91, Spearman-Brown değeri .87'dir (Bayraktar, 2001). Bu çalışmada ölçeğin Cronbach alpha katsayısı .93 olarak hesaplanmıştır.

\section{Uygulama}

Uygulama öncesinde, Denizli il merkezindeki ilkokulların anasınıfları ve uygulama anaokullarından kolay ulaşılabilirlik açısından 32 okul seçilmiştir. Bu okullar içerisinden araştırmaya katılmayı kabul eden 150 okul öncesi eğitimi öğretmeni, araştırmanın amacı, veri toplama araçları hakkında detaylı bilgi verilmiştir. Öğretmenler tüm veri toplama araçlarını doldurmuşlardır.

\section{Veri Analizi}

Veriler SPSS 16.0 veri analiz programında analiz edilmiştir. Veri analizinde Basit Doğrusal Regresyon Analizi tekniğinden yararlanılmıştır.

\section{Bulgular}

Tablo 1

Okul Öncesi Ĕ̆itimi Öğretmenlerinin Sosyal Beceri Düzeylerinin İnternet Bă̆ımlılık Düzeyleri ile İlişkisi

\begin{tabular}{|c|c|c|c|c|c|c|c|}
\hline & İBD & DA & DD & DK & SA & SD & SK \\
\hline İnt. Bağımlılık Düzeyi & 1 & & & & & & \\
\hline Duyuşsal Anlatımcılık & $-.247(* *)$ & 1 & & & & & \\
\hline Duyuşsal Duyarlık & $-.167(*)$ & $.580(* *)$ & 1 & & & & \\
\hline Duyuşsal Kontrol & $-.301(* *)$ & $.716(* *)$ & $.540(* *)$ & 1 & & & \\
\hline Sosyal Anlatımcılık & $-.164\left(^{*}\right)$ & $.568\left(^{* *}\right)$ & $.691(* *)$ & $.492(* *)$ & 1 & & \\
\hline Sosyal Duyarlık & $-.363(* *)$ & $.524(* *)$ & $.505(* *)$ & $.645(* *)$ & $.465(* *)$ & 1 & \\
\hline Sosyal Kontrol & $-.319(* *)$ & $.750(* *)$ & $.428(* *)$ & $.683(* *)$ & $.527(* *)$ & $.596\left({ }^{* *}\right)$ & 1 \\
\hline
\end{tabular}

Tablo 1'deki bulgulara göre öğretmenlerin internet bağımlılık düzeyleri ile sosyal beceri alt boyut düzeylerinin tümü arasında anlamlı bir ilişki bulunmaktadır. Buna göre öğretmenlerin internet bağımlılık düzeyleri ile Duyuşsal Anlatımcılık ( $\mathrm{r}=-$ $.247, \mathrm{p}<.001)$; Duyuşsal Duyarlık ( $\mathrm{r}=-.167, \mathrm{p}<.005)$; Duyuşsal Kontrol ( $\mathrm{r}=-.301$, $\mathrm{p}<.001)$; Sosyal Anlatımcilik $(\mathrm{r}=-.164, \mathrm{p}<.005)$; Sosyal Duyarlık $(\mathrm{r}=-.363, \mathrm{p}<.001)$; Sosyal Kontrol $(\mathrm{r}=-.319, \mathrm{p}<.001)$ düzeyleri arasında olumsuz yönde anlamlı düzeyde bir ilişki görülmektedir. Bu sonuca göre sosyal becerilerin alt boyutlarından birinin düzeyi arttıkça, internet bağımlılığı azalmakta; sosyal beceri düzeyi azaldıkça internet bağımlılığı düzeyi artmaktadır. Örnek olarak, duyuşsal anlatımcılık düzeyi yükseldikçe 
internet bağımlılığı düzeyi azalmakta; duyuşsal anlatımcılık düzeyi azaldıkça internet bağımlılığ́ düzeyi artmaktadır.

Şekil 1. Okul Öncesi Eğitimi Öğretmenlerinin Sosyal Beceri Düzeyleri ile İnternet Bağımlılık Düzeyleri Arasındaki İlişki

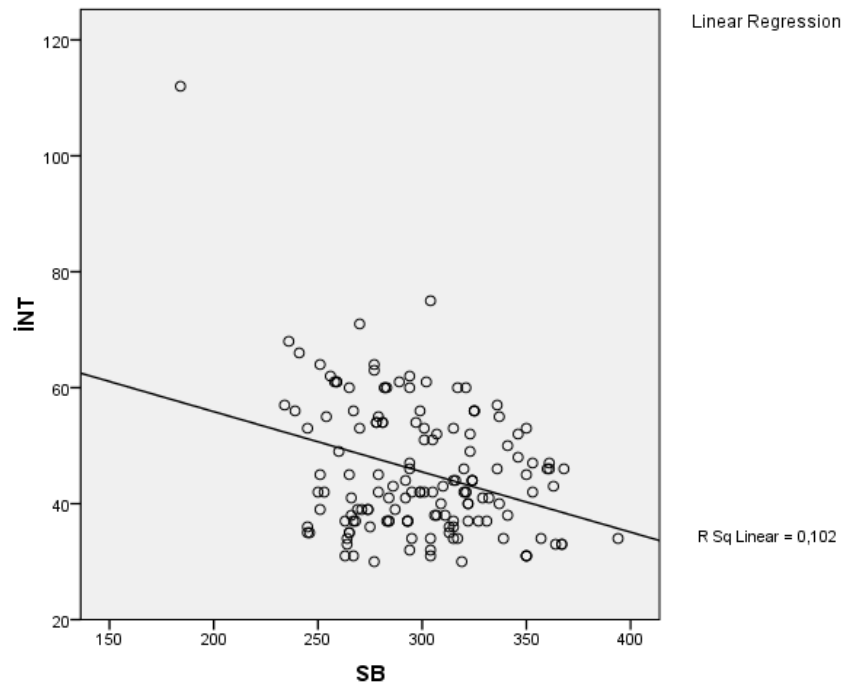

Şekil 1'de de görüldüğü gibi öğretmenlerin sosyal beceriri düzeyleri arttıkça internet bağımlılık düzeyleri düşmektedir. 
Tablo 2

Okul Öncesi Ĕ̆itimi Öğretmenlerinin Sosyal Becerilerinin İnternet Bă̆ımlılıkları Üzerindeki Yordayıcı Etkisi

\begin{tabular}{|c|c|c|}
\hline Değişkenler & $\beta$ & $t$ \\
\hline DA (Duyuşsal Anlatımcılık) & -.247 & *-3.104 \\
\hline \multicolumn{3}{|l|}{ İnternet Bağımlılı̆̆g } \\
\hline $\mathrm{R}=.25, \mathrm{R}^{2}=.061, F(1,148)=* 9.635$ & & \\
\hline DD (Duyuşsal Duyarlık) & -.167 & -2.056 \\
\hline \multicolumn{3}{|l|}{ İnternet Bağımlılı̆ğ1 } \\
\hline \multicolumn{3}{|l|}{$\mathrm{R}=.17, \mathrm{R}^{2}=.028, F(1,148)=4.226$} \\
\hline DK (Duyuşsal Kontrol) & -.301 & *-3.837 \\
\hline \multicolumn{3}{|l|}{ İnternet Bağımlılığı } \\
\hline \multicolumn{3}{|l|}{$\mathrm{R}=.30, \mathrm{R}^{2}=.090, F(1,148)=* 14.721$} \\
\hline SA (Sosyal Anlatımcılık) & -.164 & -2.027 \\
\hline \multicolumn{3}{|l|}{ İnternet Bağımlılı̆̆ } \\
\hline \multicolumn{3}{|l|}{$\mathrm{R}=.16, \mathrm{R}^{2}=.027, F(1,148)=4.110$} \\
\hline SD (Sosyal Duyarlık) & -.363 & $*_{-4.735}$ \\
\hline \multicolumn{3}{|l|}{ İnternet Bağımlılığı } \\
\hline \multicolumn{3}{|l|}{$\mathrm{R}=.36, \mathrm{R}^{2}=.132, F(1,148)=* 22.422$} \\
\hline SK (Sosyal Kontrol) & -.319 & $*_{-4.093}$ \\
\hline \multicolumn{3}{|l|}{ İnternet Bağımlılığı } \\
\hline $\mathrm{R}=.32, \mathrm{R}^{2}=.102, F(1,148)=* 16.753$ & & \\
\hline
\end{tabular}

Tablo 2 incelendiğinde, öğretmenlerin sosyal beceri alt boyutu olan Duyuşsal Anlatımcılik $\left(\mathrm{R}=.25, \mathrm{R}^{2}=.061, F(1.148)=9.635\right)$, Duyuşsal Kontrol $\left(\mathrm{R}=.30, \mathrm{R}^{2}=.090\right.$, $F(1.148)=14.721)$, Sosyal Duyarlik $\left(\mathrm{R}=.36, \mathrm{R}^{2}=.132, F(1.148)=22.422\right)$ ve Sosyal Kontrol $\left(\mathrm{R}=.32, \mathrm{R}^{2}=.102, \quad F(1.148)=16.753\right)$ düzeylerinin, internet bağımlılık düzeylerini anlamlı biçimde yordadığı görülmektedir $(\mathrm{p}<.001)$. Sosyal beceriler alt ölçeklerinden duyumsal anlatımcılık, internet bağımlılık düzeyine ilişkin varyansın \%6'sını, duyuşsal kontrol internet bağımlılığının \%9'unu, sosyal duyarlık \%13'ünü, sosyal kontrolün de internet bağımlılığının \%10'unu açıkladığı ifade edilebilir. Bu durum okul öncesi öğretmenlerinin internet bağımlılıkları üzerinde başka faktörlerinde etkili olduğunu göstermektedir. Diğer yandan standardize edilmiş regresyon katsayılarına (ß) göre okul öncesi öğretmenlerinin sosyal beceri alt boyutlarının internet bağımlılıkları üzerindeki göreli önem sırası; (1) sosyal duyarlılık, (2) sosyal kontrol, (3) duyuşsal kontrol, (4) duyuşsal anlatımcılık becerileri şeklindedir. Sonuçlara göre okul öncesi öğretmenlerinin internet bağımlılıklarını en yüksek düzeyde sosyal duyarlılık 
becerileri yordamaktadır. Ardından sosyal kontrol, duyuşsal kontrol ve duyuşsal anlatımcılık gelmektedir. Bunun yanı sıra okul öncesi öğretmenlerinin internet bağımlılıklarını sosyal beceri alt boyutlarından sosyal anlatımcılık $\left(\mathrm{R}=.16, \mathrm{R}^{2}=.027\right.$, $F(1.148)=4.110)$ ve duyuşsal duyarlık $\left(\mathrm{R}=.17, \mathrm{R}^{2}=.028, F(1.148)=4.226\right)$ boyutları anlamlı bir şekilde yordamamaktadır ( $\mathrm{p}>.001)$.

\section{Tartışma}

Okul öncesi eğitimi öğretmenlerinin sosyal becerilerinin internet bağımlılıkları üzerindeki yordayıcı etkisinin incelendiği çalışmanın sonuçlarına göre, öğretmenlerin sosyal duyarlılık, sosyal kontrol, duyuşsal kontrol ve duyuşsal anlatımcılık becerileri internet bağımlılıklarını anlamlı biçimde yordamaktadır. Sosyal anlatımcılık ve duyuşsal duyarlık becerileri ise internet bağımlılığını anlamlı düzeyde yordamamaktadır. Çalışma kapsamındaki altı sosyal beceri alt ölçeğinden dördü internet bağımlılığını yordarken, ikisi yordamamaktadır. İlgili alan yazın incelendiğinde, okul öncesi eğitimi öğretmenleriyle gerçekleştirilmiş çalışma olmamakla birlikte üniversite öğrencileri ile yapılan araştırmalarda, araştırma bulgusunu destekleyen bulgulara rastlamak mümkündür. Örnek olarak, Niemz, Griffiths, ve Banyard (2005) tarafindan Britanya'da 371 üniversite öğrencisi ile gerçekleştirilen çalışmada katılımcıların \%18.3'ünün patolojik internet bağımlısı olduğu belirlenmiştir. Çalışmada ayrıca internet bağımlılarının benlik saygılarının düşük, sosyal ilişkilerinin kısıtlı olduğu saptanmış ancak bu durumun bağımlılığın bir sonucu olabileceği gibi bağımlılığın nedeni de olabileceği vurgulanmıştır. Batıgün ve Kılıç (2011)'ın üniversite öğrencileri üzerinde yaptıkları bir çalışmanın bulgularına göre, internet bağımlılığı ölçeğinden yüksek puan alan bireylerin daha az yumuşak başl1, özdenetimlerinin düşük ve nörotizm özellikleri ile psikolojik belirtilerinin ise yüksek olduğu görülmektedir. Bu bireylerin algıladıkları sosyal destek, gelecek beklentisi ve yaşam doyumları ise daha düşük görünmektedir. Cam ve Isbulan (2013), 1235 öğretmen adayı üzerinde problemli internet kullanımı ile sosyal etkileşim kaygısı arasındaki ilişkiyi inceledikleri çalışmalarında, internet kullanım süresi arttıç̧a problemli internet kullanım durumunun da arttığını gözlemlemişler ve sosyal etkileşim kaygısının problemli internet kullanımının yordayıcısı olduğunu belirtmişlerdir. Bozoglan vd. (2013) araştırmalarında yalnızlık, benlik saygısı, hayat memnuniyeti ve internet bağımlılığı arasındaki ilişkiyi incelemişlerdir. Çalışma 18-24 yaş arasındaki 384 Eğitim Fakültesi öğrencisi ile gerçekleştirilmiştir. Araştırmada yalnızlık, benlik saygısı, yaşam memnuniyeti değişkenlerinin internet bağımlılığının \%38'ini açıkladığını belirtmişlerdir. Yalnızlığın, internet bağımlılığının en önemli yordayıcısı olduğunu vurgulamışlardır. Tutgun vd. (2011), Türkiye ve Güney Kore’ deki öğretmen adaylarının problemli internet kullanımı ile yalnızlık arasındaki ilişkiyi inceledikleri çalışmalarında, iki ülkedeki öğretmen adaylarının internet kullanımları arasında anlamlı bir fark bulamamalarına rağmen, her iki ülkedeki öğretmen adaylarının problemli internet kullanımları ve yalnızlıkları arasında zayıf fakat olumlu yönde ilişski belirlemişlerdir. Türkiye'deki devlet üniversitesinde öğrenim gören öğrencilerin problemli internet kullanımı ile çekingenlik, narsizm, yalnızlık, saldırganlık ve kişisel algılarının ilişkisinin incelendiği bir başka 
çalışmada da araştırmacılar, problemli internet kullanıcılarının utangaç ve daha saldırgan olduklarını belirtmişlerdir (Odaci ve Berber, 2013). Kurtaran (2008), yalnızlık, depresyon ve benlik saygısı değişkenlerinin ergenlerin internet bağımlılığını yordamadaki katkılarını belirlemek amacı ile gerçekleştirdiği çalışmasında, internet bağımlılığının benlik saygısını olumsuz yönde; yalnızlığın ise olumlu yönde yordadı̆̆ı, ancak depresyonun anlamlı biçimde yordamadığı görülmüştür.

Araştırmanın bulgularına göre sosyal anlatımcılık ve duyuşsal duyarlık becerileri ise internet bağımlılığını anlamlı düzeyde yordamamaktadır. Bu sonuç, araştırmadaki sosyal becerilere ilişkin alt boyutların internet bağımlılı̆̆ üzerinde aynı düzeyde etkisinin olmayabileceğini göstermektedir.

\section{Sonuç ve Öneriler}

Okul öncesi eğitimi öğretmenlerinin sosyal becerilerinin genel olarak internet bağımlılıklarını anlamlı biçimde yordayabildiği bulgusuna ulaşılan bu çalışmada bazı sınırlılıklar bulunmaktadır. Çalışma, Denizli il merkezindeki anasınıfları ve uygulama anaokullarında görev yapan 150 okul öncesi eğitim öğretmeniyle ve tarama yöntemiyle sınırlıdır. Elde edilen veriler, öğretmen görüşleriyle sınırlıdır. Sosyal beceri değişkenleri, altı alt ölçekle sınırlıdır. Çalışmanın sonuçları ve sınırlılıkları doğrultusunda alan yazın için şu öneriler geliştirilebilir. Sonraki çalışmalarda, farklı illerde ya da birden fazla ildeki daha kalabalık örneklem gruplarıyla çalışmalar yapılabilir. Öğretmen görüşlerinin yanı sıra gözlem ve/veya görüşme yoluyla veriler elde edilebilir. Öğretmenlerin internet bağımlılığı üzerinde farklı değişkenlerin (cinsiyet, mizaç, medeni durum, yaşam doyumu v.b.) etkisinin olup olmadiğ 1 incelenebilir. $\mathrm{Bu}$ çalışma, rastgele seçilmiş öğretmen grubu üzerinde gerçekleştirilmiştir. Özellikle internet bağımlılık düzeyi yüksek öğretmenlerin belirlendiği bir pilot çalışma ile çalışma planlanabilir. Okul öncesi öğretmen adaylarının öğrenciliklerinde ve meslek hayatlarında teknoloji kullanımı açısından izlendiği boylamsal çalışmalar gerçekleştirilebilir. Ayrıca okul öncesi öğretmenleri dışındaki farklı alanlardaki öğretmenlerle bu çalışma gerçekleştirilebilir. İnternet bağımlılığını önlemeye yönelik okul öncesi, ilkokul, lise ve üniversite öğrencilerini kapsayan projeler geliştirilmeli ve yaygınlaştırılmalıdır. Okul öncesi öğretmenleri başta olmak üzere tüm öğretmenlere internet bağımlılı̆̆ı, eğitim teknolojileri, teknolojinin etkili, verimli biçimde kullanılması konularında hizmet içi eğitimler verilmelidir. Öğretmenlerin ailelere, evde teknoloji kullanımı, internet bağımlılığı, çocukları hobi, spor gibi yararlı boş zaman etkinliklerine yönlendirme gibi konularda rehberlik etmeleri sağlanmalıdır. $\mathrm{Bu}$ noktada, aileleri bilgilendirici yayınlar, kamu spotları, eğitim programları hazırlanmalıdır. Türkiye'de Sosyal Beceri Eğitimi seçmeli ders olarak bazı üniversitelerin okul öncesi eğitimi öğretmenliği bölümlerinde yer almaktadır. Günümüzdeki teknoloji kullanımı, internet bağımlılığı konularındaki bulgular, okul ilkokuldan itibaren her eğitim kademesinde sosyal becerilere yönelik zorunlu derslerin olmasının, çocuklara yarar sağlayabileceğini düşündürtmektedir. Ayrıca öğretmenlerin sosyal becerilerinin çocuklar üzerindeki etkilerini ortaya koyacak araştırmalar yapılmalıdır. 


\section{Kaynakça}

Akar, E. (2010). Sanal toplulukların bir türü olarak sosyal ăg siteleri- bir pazarlama iletişimi kanalı olarak işleyişi. Anadolu Üniversitesi Sosyal Bilimler Dergisi, 10(1), 107-122.

Batıgün, D. A., ve Kılıç, N. (2011). İnternet bağımlılığı ile kişilik özellikleri, sosyal destek, psikolojik belirtiler ve bazı sosyo-demografik değişkenler arasındaki ilişkiler. Türk Psikoloji Dergisi, 26(67), 1-10.

Bayraktar, F. (2001). Internet kullanımının ergen gelisimindeki rolü. (Yayınlanmamış yüksek lisans tezi), Ege Üniversitesi, Sosyal Bilimler Enstitüsü, İzmir.

Boyd, D. M., \& Ellison, N. B. (2007). Social network sites: definition, history, and scholarship. Journal of Computer-Mediated Communication, 13(1), 210-230.

Bozoglan, B., Demirer, V., \& Sahin, I. (2013). Loneliness, self-esteem, and life satisfaction as predictors of internet addiction: A cross-sectional study among Turkish university students. Scandinavian Journal of Psychology, 54(4), 313-319.

Cam, E., \& Isbulan, O. (2012). A new addiction for teacher candidates: Social networks. Turkish Online Journal of Educational Technology, 11(3), 14-19.

Cartledge, G., \& Milburn, J. F. (1978). The case for teaching social skills in the classroom: A review. Review of Educational Research, 48(1), 111-156.

Ceyhan, E. (2008). Ergen ruh sağlığı açısından bir risk faktörü: İnternet bağımlılığı. Çocuk ve Gençlik Ruh Să̆lı̆̆ Dergisi, 15, 109-116.

Chen, J. Q., \& Chang, A. (2006). Using computers in early childhood classrooms teachers' attitudes, skills and practices. Journal of Early Childhood Research, 4(2), 168-188.

Chiu, S. I., Lee, J. Z., \& Huang, D. H. (2004). Video game addiction in children and teenagers in Taiwan. CyberPsychology \& Behavior, 7(5), 571-581. doi: 10.1089/cpb.2004.7.571

Combs, M. L., \& Slaby, D. A. (1998). Social skills training with children. Advances in Clinical Child Psychology, 1, 161-201.

Çalık, D., ve Çınar, Ö. P. (2009). Geçmişten günümüze bilgi yaklaşımları bilgi toplumu ve internet. XIV.Türkiye'de İnternet Konferanst. İstanbul: Bilgi Üniversitesi.

Çetin, E. (2009). Sosyal iletişim ağları ve gençlik: Facebook örneği. Uluslararası Davraz Kongresi, Süleyman Demirel Üniversitesi, Isparta.

Durualp, E., ve Aral, N. (2011). Oyun temelli sosyal beceri eğitimi. Ankara: Vize Yayınc1lık.

Gentilea, D. A., Lynchb, P. J., Linderc, J. R., \& Walsha, D. A. (2004). The effects of violent video game habits on adolescent hostility, aggressive behaviors, and school performance. Journal of Adolescence, 27(1), 5-22.

Göker, G., Demir, M., ve Doğan, A. (2010). A ̆g toplumunda sosyalleşme ve paylaşım: Facebook üzerine ampirik bir araştırma. E-Journal of New World Sciences Academy Humanities, 5(2), 183-206. 
Griffiths, M. D., Davies, M. N. O., \& Chappell, D. (2004). Demographic factors and playing variables in online computer gaming. CyberPsychology \& Behavior, 7(4), 479-487.

Gülay, H. (2010). Okul öncesi dönemde akran ilişkileri. Ankara: PegemA Yayıncılık.

Gülay, H., ve Akman, B. (2009). Okul öncesi dönemde sosyal beceriler. Ankara: PegemA Yayıncilık.

Hops, H. (1983). Children's social competence and skill: Current research practices and future directions. Behavior Therapy, 14, 3-18.

Horzum, M. B. (2011). İlköğretim Öğrencilerinin Bilgisayar Oyunu Bağımlılık Düzeylerinin Çeşitli Değişkenlere Göre İncelenmesi. Eğitim ve Bilim, 36(159), 5668.

Internet1. (2014). Erisim Tarihi: 20 Nisan, 2014, http://www.tuik.gov.tr/PreTablo.do?alt_id=1028

Internet2. (2014). Erisim Tarihi: 10 Nisan 2014, http://www.tuik.gov.tr/PreHaberBultenleri.do?id=15866

Jarkowski, S. (2011). Soziale kompetenzen und lernerfolg beim kooparativen Lernen. GmbH, Kassel: Kassel üniversty Press.

Kaçar, A. Ö., ve Doğan, N. (2010). Okul öncesi eğitimde bilgisayar destekli eğitimin rolü. E-Journal of New World Sciences Academy Humanities, 5(3), 472-484. Kanning, U. P. (2003). Diagnostik sozialer kompetenzen. Kompendien psychologische diagnostik. Band 4. Göttingen: Hogrefe.

Katz, L., \& McClellan, D. E. (1997). Fostering children's social competence: The teacher's role, National Association for Education of Young Children. Washington: DC: NAEYC.

King, S. A. (1996). Internet addiction. Is the internet adictive, or are addicts using the internet. Erişim 2010, http://www.webpages.charter.net/stormking/iad.html

Kurtaran, G. T. (2008). Internet bă̆ımlılı̆̆ını yordayan değişkenlerin incelenmesi. (Yayınlanmamış yüksek lisans tezi), Mersin Üniversitesi, Sosyal Bilimler Enstitüsü, Mersin.

Marko, M., Skoric, L. L., Ching, T., \& Rachel, L. N. (2009). Children and video games: addiction, engagement, and scholastic achievement. CyberPsychology \& Behavior, 12(5), 567-572. doi: 10.1089/cpb.2009.0079

Mazman, S. G. (2009). Sosyal ăgların benimsenme süreci ve eğitsel bă̆lamda kullanımı. (Yayınlanmamış yüksek lisans tezi), Hacettepe Üniversitesi, Fen Bilimleri Enstitüsü, Ankara.

Niemz, K., Griffiths, M., \& Banyard, P. (2005). Prevalence of pathological internet use among university students and correlations with self-esteem, the generalhealth questionnaire (GHQ), and disinhibition. Cyberpsychology and Behavior, 8(6), 562573. 
Odaci, H., \& Berber, Ç. (2013). Who are problematic internet users? An investigation of the correlations between problematic internet use and shyness, loneliness, narcissism, aggression and self-perception. Computers in Human Behavior, 29(6), 2382-2387.

Öztürk, Ö., Odabaşığlu, G., Eraslan, D., Genç, Y., \& Kalyon, A. Ö. (2007). İnternet bağımlılı̆̆ı: Kliniği ve tedavisi. Bă̆ımlılık Dergisi, 8(1), 36-41.

Parlak, F. (2009). Sosyal medya ve satın alma sürecine etkileri: Nitel bir uygulama. (Yayınlanmamış Yüksel Lisans Tezi), Dumlupınar Üniversitesi, Sosyal Bilimler Enstitüsü, Kütahya.

Pfeffer, S. (2012). Sozial-emotionale Entwicklung fördern. Wie Kinder in Gemeinschaft star werden. Freiburg: Verlag Herder GmbH.

Pianta, R. C. (2001). The student-teacher relationship scale. Charlottesville: University of Virginia.

Stephens, T. M. (1978). Social skills in the classroom. OH: Columbus Cedars Pres

Tutgun, A., Deniz, L., \& Moon, M. (2011). A Comparative Study of Problematic internet use and loneliness amaong Turkish and Korean prospective teachers. Turkish Online Journal of Educational Technology, 10(4), 14-30.

Vernadakis, N., Avgerinos, A., Tsitskari, E., \& Zachopoulou, E. (2005). The use of computer assisted instruction in preschool education: Making teaching meaningful. Early Childhood Education Journal, 33(2). doi: 10.1007/s10643-005-0026-2

Yang, S. C., \& Tung, C. (2004). Comparison of internet addicts and non-addicts in Taiwanese high school. Computers in Human Behavior, 23, 79-96.

Yaşar, Ş. (2004). Okulöncesi eğitimde bilgisayar öğretimi. Eskişehir: Anadolu Üniversitesi Yayınları.

Young, K. S. (1996). Internet addiction: The emergence of a new clinical disorder. Cyberpsychology and Behavior, 1(3), 237-244.

Yüksel, G. (1998). Sosyal beceri envanterinin Türkçe’ye uyarlanması: Geçerlik ve güvenirlik çalışmaları. Psikolojik Danışma ve Rehberlik Dergisi, 9, 39-48. 